\title{
LOS EFECTOS DE LA VOLUNTARIEDAD DEL VOTO Y DE LA INSCRIPCIÓN AUTOMÁTICA EN CHILE
}

\author{
Patricio Navia \\ Universidad Diego Portales/New York University \\ Belén del Pozo Quevedo \\ Universidad Diego Portales
}

Resumen: La reforma constitucional de 2009 que estableció la voluntariedad del voto en Chile y la reciente reforma que estableció la inscripción automática incuestionablemente tendrán efectos sobre la tasa de participación electoral y también sobre los resultados de las futuras contiendas. Si bien la inscripción automática aumentará dramáticamente el número de electores potenciales, pasando de 8,5 a más de 13,3 millones de personas, la voluntariedad del voto podría afectar negativamente la participación electoral, ya que todos los votantes que así lo deseen podrán abstenerse de asistir a las urnas, sin quedar sujetos a sanciones legales por no concurrir a votar. En base a datos de la encuesta de opinión pública del CEP

Patricio Navia. Ph. D. y MA en ciencia política, New York University y University of Chicago, respectivamente. Profesor titular de la escuela de ciencia política de la Universidad Diego Portales y master teacher en el departamento de Liberal Studies de New York University. Dirección electrónica: Patricio.navia@ nyu.edu.

Belén del Pozo Quevedo. Alumna de cuarto año en la licenciatura de ciencia política e investigadora asistente del Observatorio Electoral de la Universidad Diego Portales. Dirección electrónica: belendelpozoq@gmail.com. 
de octubre de 2009, que indagó sobre las preferencias e inclinaciones políticas de los chilenos, y sobre su disponibilidad a votar, estudiamos los posibles efectos que habrían tenido estas dos reformas tanto sobre la participación electoral como sobre los resultados de las elecciones de 2009. Mostramos que, de haber habido inscripción automática y voto voluntario en las elecciones de 2009 (esto es, si se hubiesen abstenido los inscritos que preferían no votar y hubiesen votado los no inscritos que sí estaban dispuestos a acudir a las urnas), las preferencias del electorado no habrían variado demasiado, pero el universo de votantes habría sido más joven y más representativo de la población adulta del país que el electorado que votaba con el anterior sistema.

Palabras clave: participación electoral, abstención electoral, sistema de partidos, preferencias políticas.

Recibido: enero 2012; aceptado: junio 2012.

\section{THE EFFECTS OF VOLUNTARY VOTING AND AUTOMATIC REGISTRATION ON TURNOUT IN CHILE}

Abstract: The 2009 constitutional reform that made voting non-mandatory and the recent reform that established automatic registration will undoubtedly have effects on turnout rates and on the results of future elections. Though automatic registration has increased the number of registered voters from 8.5 to more than 13.3 million, voluntary voting could negatively affect turnout since all potential voters -new and old-will have the option to abstain, without the fear of a fine or legal retaliation. Using the Centro de Estudios Públicos poll of October 2009, on electoral and political preferences of Chileans and on their disposition to turnout, we analyze the potential effect of these two reforms on turnout and on likely electoral results in the December 2009 elections. We show that the overall preferences of the electorate would not have varied in 2009 if those previously registered that wished to abstain had done so and those newly registered that wished to vote had also done so. We also show that voting population would have been younger and more representative of the voting age population than the actual voting population in recent elections.

Keywords: electoral turnout rates, electoral absenteeism, party system, political preferences.

Received: January 2012; accepted: June 2012. 
$\mathrm{E}_{\mathrm{n}}$ las elecciones presidenciales de 2009 votaron 7,2 millones de chilenos. Si bien eso representa el 87,8\% del padrón electoral, a fines de 2009 había más de 4,3 millones de personas que no se habían inscrito para votar. Medido como porcentaje de personas en edad de votar (PEV), sólo el 57,6\% participó en la contienda de 2009. El singular sistema de inscripción voluntaria y votación obligatoria que tuvo Chile hasta fines de 2011 obligaba a las personas que se habían inscrito en los registros electorales a votar (aunque el día de la elección no hubiesen querido concurrir a las urnas). Sin embargo, aquellas que no se inscribían dentro de los plazos establecidos para hacerlo (porque la ley no obligaba a inscribirse) no podían votar aunque el día de la elección hubiesen querido hacerlo. La eliminación de la obligatoriedad del voto y la automatización de la inscripción electoral han alimentado especulaciones sobre los efectos que estas reformas tendrán en los patrones de votación relativamente estables de años recientes. Usando encuestas de opinión, analizamos posibles cambios en las tasas de participación electoral dadas las distintas combinaciones de obligatoriedad del voto y automatización de la inscripción electoral, y qué tanto se diferenciarían las preferencias del universo de votantes que votó en las elecciones de 2009 de las del universo integrado por los inscritos y no inscritos en octubre de 2009, que manifestaban disposición a votar. Después de repasar las teorías que dan cuenta del porqué de la participación electoral y de la formación de inclinaciones políticas, analizamos la evolución del comportamiento electoral de los chilenos desde el retorno de la democracia. Luego, usando datos de encuestas del Centro de Estudios Públicos (CEP), discutimos los escenarios que podrían darse bajo el nuevo sistema de inscripción automática y voto voluntario. Si bien cambiará sustancialmente la composición etaria del electorado, concluimos que las preferencias electorales e inclinaciones políticas mostrarían bastante estabilidad.

\section{1. ¿Por qué vota la gente?}

\subsection{Análisis costo-beneficio}

El teorema del votante mediano sugiere que en una elección a dos bandas, ambos candidatos buscan satisfacer las preferencias del votante más moderado para de este modo maximizar la posibilidad de 
ganar (Downs 1957; Downs 2001). Como resultado, el votante mediano -aquel que se ubica en las posiciones más moderadas del espectro político- es indiferente, ya que no habrá mayor diferencia en las políticas que implementen uno $u$ otro candidato. Luego, ambos candidatos tienen igual posibilidad de triunfo. En este modelo, la participación es obligatoria. Pero cuando la votación es voluntaria, ¿por qué molestarse en escoger entre dos candidatos que ofrecen lo mismo? Peor aún, ¿por qué alguien participaría en un proceso electoral donde su probabilidad de influir en el resultado es mínima?

Riker y Odershook (1968) entienden esta paradoja de la participación como una función de utilidad que incluye: los beneficios de votar, la probabilidad de que el voto sea decisivo y los beneficios que implica la victoria del candidato favorito (Uhlaner 1995). Puesto que las políticas propuestas por ambos candidatos son similares, los beneficios esperados de esas políticas no varían mucho. Por eso, un valor marginalmente alto del costo de votar redundará en altos niveles de abstención. Cuando la votación es obligatoria, la paradoja de la participación no desaparece: los electores pueden anular o votar en blanco.

Downs sugirió que los ciudadanos están dispuestos a incurrir en los costos que implica votar (Downs 2001: 67.) Pero la provisión de un gobierno democrático (esto es, un gobierno elegido por la ciudadanía), como suele ocurrir con la provisión de bienes públicos como éste, presenta un problema de acción colectiva. Aldrich (1993: 48), por ejemplo, sostiene que los ciudadanos adoptan posturas de free riders y se abstienen, obteniendo el beneficio de la democracia sin pagar su costo. Por otro lado, Ferejohn y Fiorina (1974: 527) señalan que como no es posible anticipar el comportamiento de otros votantes, los electores no saben si su voto será decisivo, por lo que una participación alta no sería incompatible con un comportamiento racional de costo-beneficio.

\subsection{Variables institucionales}

Según Powell Jr. (1986: 21), la participación también está relacionada con el contexto competitivo de elecciones y con factores institucionales. Agrega que la variable de predicción más poderosa de la participación electoral es la inscripción automática (1986: 25). Mitchell y Wlezien (1995) sostienen a su vez que las leyes restrictivas de inscripción afectan negativamente la participación. Otros también han señalado 
que cambios relativamente menores en el diseño institucional pueden incidir en el número de personas que votan (Jackman y Miller 1995; Lijphart 1997: 7). Y ceteris paribus, advierte Grofman (1995: 102): "la participación electoral es menor [...] cuando las barreras de inscripción electoral son altas y cuando a poca gente le preocupa el resultado de la elección". Campbell et al. (1960) también argumentan que las restricciones para que los ciudadanos se incorporen al padrón (como la inscripción presencial en registros electorales, y horarios y periodos limitados de atención) reducen la tasa de participación electoral, especialmente entre los más pobres y menos educados. Por el contrario, facilitar la inscripción genera mayor participación electoral entre las personas con menos educación (Mitchell y Wlezien 1995; Highton 1997). Por su parte, Wolfinger y Rosenstone (1980) señalan que reducir las restricciones para inscribirse tendría efectos positivos sobre el nivel de votación.

Highton (1997), en su estudio comparado sobre la relevancia de la facilidad de de inscribirse para votar (easy registration) en Estados Unidos, encuentra evidencia de su efecto en la participación electoral. De acuerdo a Highton, las personas con menor nivel educacional concurren más a las urnas en aquellos estados que imponen mínimos o nulos costos para registrarse. Por otra parte, Blais, Massicotte y Dobrzynska (2003) realizaron una escala indicadora (scale indicating) para evaluar el impacto de la posibilidad de votar en forma anticipada o a distancia o por correo (advance, postal or proxy voting), concluyendo que existía una relación directa con el nivel de votación: a mayores facilidades para votar, mayor participación electoral.

La disminución de las barreras de entrada reduce ciertos costos asociados con la participación, pero no determina, por sí sola, la composición de los que se registran o votan. Al disminuir las barreras, se puede producir un electorado menos interesado en la política y más volátil. Mitchell y Wlezien (1995) sostienen que al ingresar al electorado personas que previamente no participaban, se deduce que serán votantes poco interesados, lo que generaría un incremento en la volatilidad del electorado.

Podríamos pensar que un sistema multipartidista produce una mayor participación ya que los votantes tienen más opciones entre las cuales elegir, lo que aumentaría su disposición a concurrir a las urnas. Blais (2008a: 628), sin embargo, advierte que "un sistema multipartidista usualmente conlleva la formación de coaliciones políticas, debido 
a lo cual las elecciones podrían ser menos decisivas [para los electores] dado que la composición final de dichas coaliciones depende de la coordinación que los partidos lleven a cabo". Por cierto, ya que informarse acerca de las diferentes posibilidades implica costos para los potenciales votantes, la existencia de un mayor número de partidos o candidatos tendría efectos negativos sobre la participación.

Por otro lado, se ha sugerido que las personas estarían menos predispuestas a votar cuando el sistema electoral es de tipo proporcional, ya que sienten que su voto no será decisivo (Franklin 2004, por ejemplo). Pero otros han argumentado que los sistemas electorales de representación proporcional (RP) aumentan la concurrencia a las urnas (Powell Jr. 1986; Jackman 1987; Blais and Carthy 1990; Franklin 1996; Franklin 2004), cuestión que también parece ser cierta en América Latina (PérezLiñán 2001; Fornos, Power et al. 2004). Sin embargo, tal como señala el mismo Blais (2008b), no hay evidencia suficiente para aseverar de manera categórica el impacto global del sistema electoral sobre la votación, ya que algunos elementos de ciertos sistemas favorecen la participación mientras que otros tienden a afectarla negativamente.

Asimismo, el tipo de elección - en particular la importancia de los cargos a elegirse - estaría directamente relacionado con el nivel de participación electoral (Blais 2008a). En sistemas presidenciales, adquieren mayor importancia las elecciones para primer mandatario. En Latinoamérica, luego de las transiciones democráticas de varios países durante la década de los 80 , se registraron altas tasas de votación. Sin ir más lejos, en el plebiscito de 1988 en Chile rondó cerca del 90\% (Navia 2004).

\subsection{Variables culturales, etarias, educacionales y socioeconómicas}

Pero la participación electoral implica una racionalidad más compleja que una consideración exclusiva de costos y beneficios económicos o de conveniencia individual. De ahí que las razones con que a menudo se defienden la obligatoriedad o voluntariedad del voto suelan ser de carácter normativo. Almond y Verba (1963) postularon una relación entre valores culturales y participación política. Años después, Ferejohn y Fiorina (1974) y Powell Jr. (1986) encontraron que por motivos idiosincrásicos ciertos grupos participan más en política. En 
su análisis sobre el comportamiento electoral, Montecinos (2007: 13) sugiere que variables psicológicas tales como carácter cívico y valoración personal del individuo respecto al acto de asistir a votar explican la participación. A mayor nivel de valoración cívica, mayor disposición a votar. La condición social del individuo, por otro lado, es un factor influyente en el valor que asigne al acto de asistir a votar, así como influirá la aprobación de su grupo social. Las personas de mayores niveles de educación y más ingresos tienen mayor predisposición a votar (Montecinos 2007: 14).

En cuanto al factor edad, hay multiplicidad de estudios acerca de su incidencia en la participación electoral. Las personas jóvenes participan menos (Franklin 2004; Rubenson, Blais et al. 2004), y la participación es menor en jóvenes con bajos niveles de educación (Lyons y Alexander 2000). En Estados Unidos y Europa, la participación electoral es mayor en grupos con mayor nivel educacional (Powell 1986: 28) y entre votantes de mayor edad (Powell 1986: 30). La variable generacional (Franklin 2004; Rubenson, Blais et al. 2004) es considerada una de las más significativas para explicar el declive constante de la participación electoral en muchas democracias occidentales (Blais 2008b; Corvalán y Cox 2010). Una de las principales razones que explican la disminución en el nivel de votación en Estados Unidos es el remplazo de la generación del New Deal (los nacidos antes de 1932) con la generación del Post-New Deal generation (los nacidos después de 1964), que participan menos (Miller y Shanks 1996). Las nuevas generaciones también son menos propensas a identificarse con partidos, tienen una baja integración con la comunidad y poco interés en la política (Miller y Shanks 1996).

En la vereda opuesta, Franklin (2004) plantea que más importante que el cambio en el "carácter" de los votantes es el cambio en el "carácter" de las elecciones. Una de las razones de declive de los niveles de votación es the young initiation (la iniciación juvenil). Su proposición apunta a que los jóvenes enfrentan sus primeras elecciones en un muy mal momento, cuando ingresan a la universidad, comienzan a trabajar o a insertarse en la comunidad.

Por cierto, considerar el factor generacional como variable explicativa de la participación electoral puede ser pertinente al analizar lo ocurrido después de la década de los 80 en Chile. La transición a la democracia puede ser un hecho histórico relevante para explicar la caída 
en participación (the turnout decline). Para el caso chileno, un estudio reciente (Corvalán y Cox 2010) aporta dos conclusiones novedosas. El electorado joven aparece fuertemente sesgado por clase social (class biased), donde el nivel de ingreso es una variable explicativa importante en la composición del registro y votación en los jóvenes. En segundo lugar, los efectos generacionales son particularmente fuertes, considerando que las reglas de registro electoral vigentes hasta 2011 hicieron que los ya inscritos se mantuvieran permanentemente en el padrón. El quiebre generacional lo producía la intensa experiencia política que tenían los electores que participaron en el plebiscito, en contraposición a quienes cumplieron 18 años cuando ya se había producido la transición.

\section{La participación electoral en Chile}

\subsection{Revisión de la literatura}

La participación electoral en Chile ha sido estudiada en sus dimensiones de declive (Navia 2004; Carlin 2006; Toro 2007; Toro 2008; Saldaña 2009), aumento de la abstención (Parker 2000; Parker 2003; Cantillana 2009) y votación nula y blanca (Carlin 2006; López y Pirinoli 2009). También ha habido interés por el nivel de participación de los jóvenes (Lehmann 1998; Parker 2000; Parker 2003; Instituto Nacional de la Juventud 2004; Toro 2007; Toro 2008; Corvalán y Cox 2010). Mientras algunos plantean la hipótesis del cambio generacional, considerando variables sociodemográficas y de actitudes políticas (Toro 2008; Corvalán y Cox 2010), otros proponen comprender la participación política de manera holística (Angelcos 2011; Thezá 2011). En años recientes, además, se especuló sobre los efectos que generaría una reforma al sistema de votación (Navia 2004; Fuentes y Villar 2005; Fontaine, Larroulet et al. 2007; Morales 2011; Contreras, González et al. 2012, por publicarse), considerando, en general, la experiencia comparada para predecir cuáles serían los efectos de tal reforma.

En la configuración de una estructura bipolar de coaliciones y un electorado que "permanece fiel a las dos coaliciones surgidas del plebiscito de 1988", Tironi y Agüero identificaron un nuevo clivaje, autoritarismo versus democracia, que explicaba la formación, con el retorno a la democracia, de un sistema de pluralismo moderado con "menor 
distancia ideológica y una competencia centrípeta" (1999: 155 y 159). Aunque formalmente lo definieron como un clivaje social, la postura de Tironi y Agüero es más bien consistente con el postulado de la Escuela de Michigan, que argumenta que la identificación partidaria resulta de procesos de socialización, como lo fue la transición a la democracia a fines de los 80 (Campbell, Converse et al. 1960; Miller y Shanks 1996). Convincentemente, Valenzuela cuestiona el uso del concepto "clivaje" para referirse al reordenamiento ocurrido en torno a la transición, destacando que este reordenamiento más bien responde a los efectos de un nuevo sistema electoral y que el antiguo ordenamiento del sistema de partidos en torno a tercios - izquierda, centro y derecha - continúa vigente (Valenzuela 1999). Como sea, la formación de un nuevo clivaje no involucra necesariamente la desaparición de clivajes previos. Ambos pueden coexistir. Como exponen López y Morales (2005), "los factores de largo plazo mantienen vigencia [pero] los acontecimientos pre 1973 van perdiendo capacidad explicativa en todos los grupos" (López y Morales 2005: 105). Los procesos de socialización se pueden producir a partir de fuertes cambios políticos, como presumiblemente ocurrió con el plebiscito de 1988 y la posterior transición a la democracia, proceso que además conllevó la creación de un nuevo sistema electoral. Cambios sociales de este tipo pueden ser perdurables a pesar de lo breve de sus procesos (Navia, Briceño Espinoza et al. 2009: 13).

Estudios sobre la socialización política en Chile, enmarcados en el modelo Michigan, han encontrado que la socialización política ayuda a entender las preferencias electorales y también la participación electoral. Toro señala que la frecuencia de las conversaciones con padres y amigos aumenta en 7,2\% la probabilidad de los jóvenes de inscribirse (Toro 2007). Otros plantean que la caída en la participación electoral se da fundamentalmente entre aquellos chilenos que no vivieron la transición a la democracia (Contreras y Navia 2012) y se evidencia aún más entre aquellos de menores ingresos (Corvalán y Cox 2010).

Finalmente, la Escuela de Rochester considera que variables de corto plazo son predominantes para explicar el comportamiento de las personas, y presumiblemente también su disponibilidad a votar. Esta corriente se inspira en la teoría del votante racional (Downs 1957), que propone que los individuos evalúan sus alternativas de acuerdo a los costos y beneficios de cada opción, condicionados por asimetrías de información y por sus propias creencias. Así, según Duch y Stevenson 
(2008), la evaluación sobre el desempeño económico e incluso la evolución política del país explicarían las preferencias electorales de la gente, pero también su probabilidad de votar. La Escuela de Rochester considera que si el gobierno saliente obtuvo buenos resultados económicos, el electorado mantendrá una preferencia por el partido o coalición de gobierno. Hay diversos estudios que han aplicado estos modelos al caso de Chile (Dow 1998; Bonilla, Carlin et al. 2009). Esa misma lógica llevaría a las personas a decidir si participarán del proceso electoral.

\subsection{Evolución de la inscripción}

Como se observa en la Figura $\mathrm{N}^{\circ}$ 1, la población en edad de votar (PEV) en Chile ha aumentado de forma constante desde el retorno de la democracia en 1990. No obstante, el número de inscritos se mantuvo estable hasta 2009, aumentando a un ritmo inferior al aumento de la PEV. Desde 1990 hasta diciembre de 2011, el número de inscritos mostró una

FIGURA N ${ }^{\circ}$ 1: $\quad$ EVOLUCIÓN DE POBLACIÓN EN EDAD DE VOTAR Y POBLACIÓN INSCRITA, 1988-2011

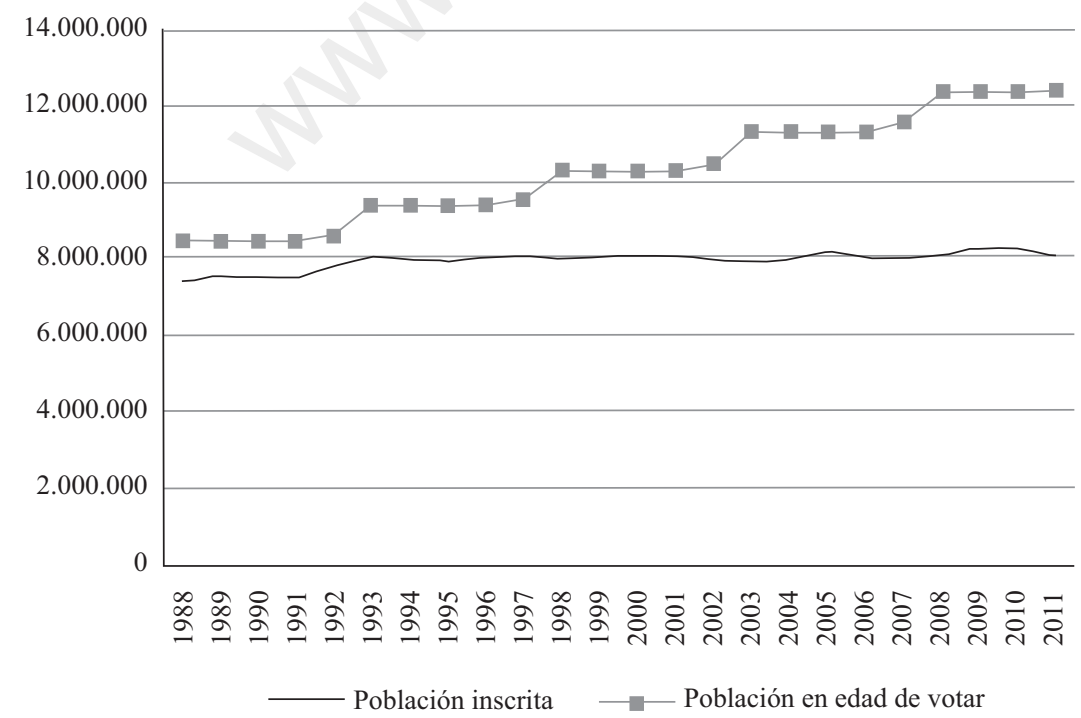

Fuente: Elaboración propia con datos de www.ine.cl y www.elecciones.gov.cl. 
estabilidad sorprendente, lo que implica que fue aumentando el número de chilenos que no se inscribían para votar y que, por tanto, quedaban fuera del padrón. A su vez, el número de inscritos siempre crecía en los meses anteriores a una elección. Cuando el país se polarizaba antes de una campaña, la probabilidad de que se inscribieran aquellos que no estaban en el padrón también aumentaba.

La Figura $\mathrm{N}^{\circ} 2$ muestra la evolución del padrón electoral desde abril de 2009 hasta octubre de 2011. En los meses inmediatamente anteriores a la elección presidencial, el número de inscritos creció de poco más de 8 millones a 8,3 millones. Los registros electorales se cerraron en septiembre de 2009. Cuando se volvió a abrir el padrón en abril de 2010, la eliminación de todos los fallecidos en el periodo en que el padrón estuvo cerrado hizo caer el número de inscritos a poco más de 8,2 millones.

Ya que para votar se requería estar inscrito en los registros, es preciso detenerse en este requisito. Hasta la reciente reforma que estableció la inscripción automática en los registros electorales, el trámite

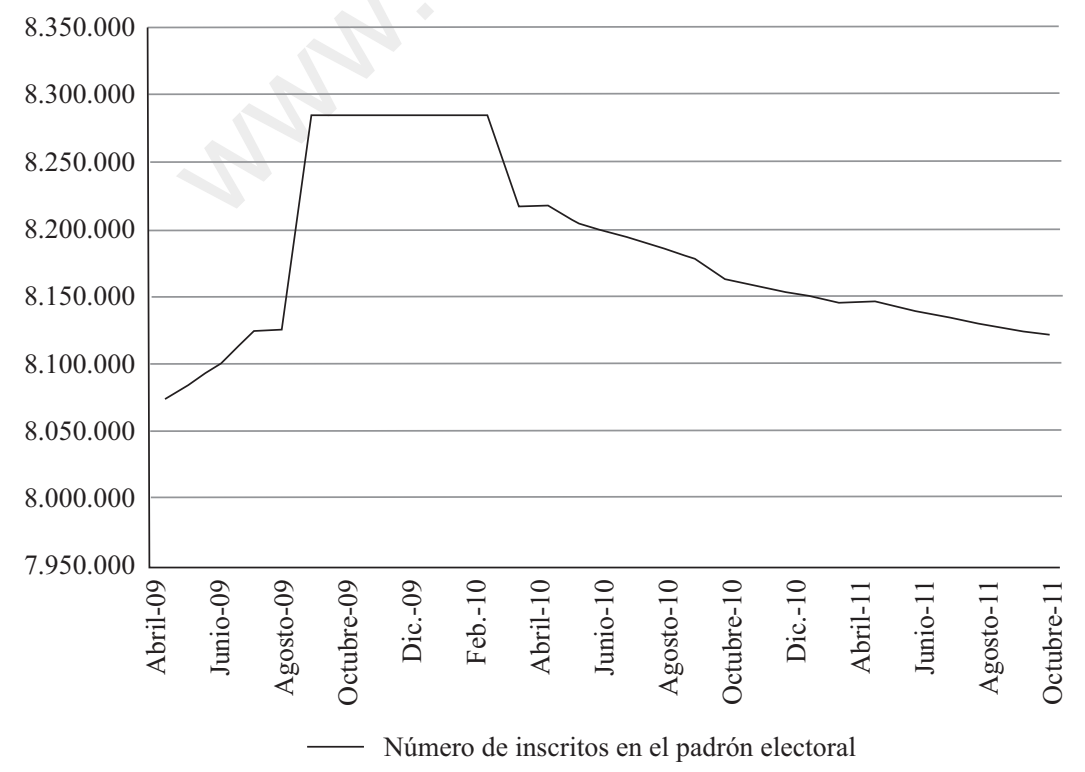

Fuente: Elaboración propia con datos de www.servel.cl. 
de inscripción era presencial, de ahí que se considerara que la inscripción era "voluntaria". Una vez inscrito, sin embargo, el individuo tenía la obligación de concurrir a votar, de lo contrario corría el riesgo de ser multado, por una cantidad variable entre $1 / 2$ y 3 UTM (el valor de una unidad tributaria mensual era aproximadamente de 40 mil pesos, US\$80, a fines de 2011). Pero no había políticas activas para multar a aquellos que no cumplían con su obligación.

La disminución del padrón electoral ha sido atribuida a dos causas. Por un lado, al supuesto descontento o desafección de los chilenos con el proceso político. Por otro lado, a una institucionalidad que obligaba a inscribirse en los registros electorales para ejercer el derecho a voto. Navia (2004) argumentó que el nivel de participación a fines de los 90 era similar al existente antes de 1973, sugiriendo que el plebiscito de 1988 fue un hecho anómalo que, debido a la importancia de la elección, produjo un aumento importante en la tasa de inscritos. Por lo tanto era lógico esperar que el nivel de inscritos disminuyera después (Navia 2004). Otros argumentan que sí hay tal desafección y que ésta se evidenciaría en decrecientes tasas de participación (Moulián 1997; Brunner 1998; Huneeus 1998; Tironi 1999), especialmente en los grupos etarios más jóvenes. Según Toro (2007: 106), la desafección de la población joven "refleja nuevos valores e intenciones que tienden a generarse en orden a los intereses individuales y de protesta" (2007: 106), y que sus formas de protestas no se materializan dentro del sistema institucional sino que fuera de él, como ocurre con la abstención. Desmitificando el argumento de que la abstención reflejaría valores diferentes, Rubilar (2009) muestra sin embargo que los jóvenes y no jóvenes tienen similares niveles de identificación con partidos o escala ideológica.

La discusión sobre las causas de los bajos niveles de participación de los más jóvenes - y su supuesta mayor desafección- lleva años en el debate público. Los informes del Programa de las Naciones Unidas para el Desarrollo (PNUD 1998; PNUD 1999; PNUD 2000; PNUD 2004) asocian el supuesto malestar con los crecientes niveles de incertidumbre y vulnerabilidad que existen en la sociedad. Los informes del PNUD sugieren que las decisiones sobre la participación en política se toman bajo un fuerte criterio subjetivo, que desemboca en una paradoja: "en el momento mismo en que el ciudadano puede incidir con voz y voto en las orientaciones básicas del desarrollo [...] la participación política se debilita" (PNUD 1998: 52). Aunque el supuesto es que la 
desafección representa un malestar social, el estudio también afirma que puede obedecer a que el rápido proceso de modernización ha descolocado a la sociedad chilena. Por eso, un informe del PNUD concluía subrayando la paradoja de "un país con un notable desarrollo económico, donde la gente no se siente feliz" (PNUD 1998: 52).

Si bien es razonable suponer que los jóvenes tienen menos predisposición a votar, el hecho de que aquellos que cumplieron 18 años con posterioridad al retorno de la democracia hayan mantenido bajas tasas de inscripción a medida que envejecían deja en evidencia que lo observado no responde exclusivamente a un fenómeno de menor participación electoral sólo de jóvenes (Contreras y Navia 2012). Autores que abogaron por la inscripción automática en el sistema chileno consideraban que el proceso de inscripción era una de las principales barreras de entrada (Ortega, 2003: 113). Al automatizarse la inscripción, el universo electoral ha aumentado de 8,5 a más de 13,3 millones de personas. Sin embargo, nada asegura que los nuevos inscritos voten. Aunque hayan disminuido los costos de votar, puede aumentar la apatía (Mitchell y Wlezien 1995) y la participación podría caer aún más (Morales 2011).

De ahí que amerite indagarse qué efectos tendrán sobre la participación electoral la inscripción automática y la votación voluntaria aprobadas recientemente.

\section{Disposición a votar del electorado chileno}

Para estimar la disposición a votar de los chilenos, utilizamos la encuesta de opinión realizada por el Centro de Estudios Públicos (CEP) en octubre de 2009, poco antes de las elecciones de diciembre de ese año, comparando a los inscritos con los no inscritos y controlando por variables diferentes variables.

\subsection{Edad, grupo socioeconómico, percepción de la economía y disposición a votar}

La Tabla $\mathrm{N}^{\circ} 1$ muestra las cuatro combinaciones posibles de personas en edad de votar, a partir de las distintas posibilidades de inscripción (voluntaria o automática) y votación (obligatoria o voluntaria). Las columnas muestran el porcentaje de personas inscritas en el registro 
electoral, mientras que las filas muestran el porcentaje tanto de aquellos que, estando inscritos, manifestaron que votarían si la votación fuese voluntaria, como de aquellos que no estando inscritos, expresaron que votarían si la inscripción fuese automática. En la encuesta CEP de octubre de 2009 - la única en años recientes que específicamente indagó sobre la predisposición a votar- el porcentaje de inscritos alcanzaba al $72,6 \%$ de la muestra. De ellos, cuatro de cada cinco declararon que votarían si la votación fuese voluntaria. A su vez, del 27,2\% de los no inscritos, dos de cada tres personas indicaron que votarían si la inscripción fuese automática. Con el sistema entonces en vigencia de inscripción voluntaria y votación obligatoria, la participación habría alcanzado (según la muestra) al 72,6\%, de los inscritos. De haber habido inscripción automática y votación voluntaria, el $76,1 \%$ de la muestra habría votado. Curiosamente, entonces, la participación electoral en 2009 no habría sido muy distinta con o sin inscripción automática y voto voluntario. Ahora bien, la participación efectiva en 2009 fue de 87,7\% (84,2\% si se consideran sólo los votos válidamente emitidos) sobre un padrón de 8,3 millones de inscritos. Si se mantuviera esa participación efectiva con el nuevo padrón de 13,4 millones de inscritos en 2012, deberían votar más de 11,3 millones de personas. Si, en cambio, asumimos una tasa de participación de $76,1 \%$, esperaríamos una participación de 10,2 millones de personas. Pero claro, la pregunta de 2009 era sobre una situación

TABLA N ${ }^{\circ}$ 1: $\quad$ CONDICIÓN DE INSCRIPCIÓN Y DISPONIBILIDAD A VOTAR, 2009-2011

\begin{tabular}{lccc}
\hline Disposición a votar & $\begin{array}{c}\text { Inscritos } \\
\text { \% (número })\end{array}$ & $\begin{array}{c}\text { No inscritos } \\
\text { \% (número) } \\
\text { Octubre de 2009 }\end{array}$ & $\begin{array}{c}\text { Total } \\
\text { \% (número) }\end{array}$ \\
\hline Votarían & 59,0 & 18,1 & 76,1 \\
No votarían & 13,6 & 9,1 & 22,7 \\
Total & $72,6(1.092)$ & $27,2(409)$ & $98,8^{*}$ \\
\hline
\end{tabular}

* No suma 100, por un porcentaje mínimo que no indica condición de inscripción electoral.

Fuente: Elaboración propia con datos de Encuesta CEP N 61, octubre 2009, CEP $\mathrm{N}^{\circ} 64$, julio de 2011. 
hipotética. Dado que cada elección es distinta —el interés en participar en una contienda presidencial tiende a ser mayor que en una contienda municipal - resultaría equivocado intentar predecir a partir de elecciones anteriores la tasa de participación en un contexto de inscripción automática y voto voluntario.

La Tabla $\mathrm{N}^{\circ} 2$ muestra la edad promedio de las personas que componían cada grupo en 2009. Los inscritos que votarían tienen una edad levemente superior (55,2 años) a la de los inscritos que no votarían (49,5 años.) Entre los no inscritos, la edad promedio de los que estarían dispuestos a votar es similar a la edad promedio de los que no estarían dispuestos a hacerlo. Ya que hay menor disponibilidad a votar entre los más jóvenes, la edad promedio de todos los que no votarían es inferior $(41,2)$ a la edad promedio de los que sí votarían (49 años). La Tabla $\mathrm{N}^{\circ} 2$ confirma una mayor predisposición a votar entre las personas de más edad, lo que es consistente con la literatura respecto a la participación electoral (Franklin 2004).

Pero entre los no inscritos la disposición a votar no aumenta a medida que las personas envejecen. Si bien el grueso de los no inscritos cumplió 18 años después de 1988 - por lo que en 2009 se ubicaba en el rango etario inferior a 40 años de edad—, la disposición a votar no es superior entre las personas más cercanas a los 40 años que entre los que recién han cumplido 18 años. Esta tendencia es contraria a lo que sugiere la literatura, que señala que la disposición a votar aumenta a medida que aumenta la edad (Franklin 2004).

Como se aprecia en la Tabla $\mathrm{N}^{\circ} 3$, el porcentaje de inscritos dispuestos a votar es mayor en los grupos socioeconómicos más altos. Si

TABLA N ${ }^{\circ}$ 2: $\quad$ EDAD PROMEDIO EN LOS DISTINTOS GRUPOS SEGÚN DISPOSICIÓN A VOTAR

\begin{tabular}{llll}
\hline Disposición a votar & Inscritos & No inscritos & Total \\
\hline Votarían & & & \\
No votarían & 55,2 & 28,9 & 49,0 \\
Total & 49,6 & 28,6 & 41,2 \\
& $54,2(1.093)$ & $28,6(409)$ & $47,3(1.502)$ \\
\hline
\end{tabular}

Fuente: Elaboración propia con datos de Encuesta CEP № 61, octubre 2009. 

POR GSE

\begin{tabular}{|c|c|c|c|c|c|}
\hline & $\begin{array}{l}\text { Inscritos dispuestos } \\
\text { a votar } \\
\text { (a) }\end{array}$ & $\begin{array}{l}\text { No inscritos } \\
\text { dispuestos } \\
\text { a votar } \\
\text { (b) }\end{array}$ & $\begin{array}{c}\text { Dispuestos a } \\
\text { votar (inscritos } \\
\text { y no inscritos) } \\
(\mathrm{c}=\mathrm{a}+\mathrm{b})\end{array}$ & $\begin{array}{l}\text { Inscritos y no } \\
\text { inscritos que } \\
\text { prefieren no votar } \\
\text { (d) }\end{array}$ & $\begin{array}{c}\text { Total } \\
\% \text { (Núm.) } \\
(\mathrm{e}=\mathrm{c}+\mathrm{d})\end{array}$ \\
\hline $\mathrm{ABC} 1$ & 88,6 & 7,6 & 96,2 & 3,8 & $100(79)$ \\
\hline $\mathrm{C} 2$ & 74,1 & 10,5 & 84,6 & 15,4 & $100(143)$ \\
\hline $\mathrm{C} 3$ & 56,2 & 18,2 & 74,3 & 25,7 & $100(584)$ \\
\hline D & 56,1 & 20,7 & 76,8 & 23,2 & $100(663)$ \\
\hline $\mathrm{E}$ & 40,6 & 28,1 & 68,8 & 31,3 & $100(32)$ \\
\hline Total & 59,9 & 18,2 & 77,4 & 22,6 & $100(1.501)$ \\
\hline
\end{tabular}

Pearson Chi Square: 52.936** (estadísticamente significativo al 0.001).

Fuente: Elaboración propia con datos de Encuesta CEP N 61 , octubre 2009.

en el grupo E es del 40,6\%, en el ABC1 llega al 88,6\%. Si incluimos los no inscritos dispuestos a votar, el 96,2\% del $\mathrm{ABC} 1$ estaría dispuesto a votar. En los grupos socioeconómicos más bajos disminuye la disposición a votar. Pero aun así la participación en los grupos $\mathrm{D}$ y E sería mayor con inscripción automática que con el sistema antiguo de inscripción voluntaria y voto obligatorio. La inscripción automática aumentaría la participación en los sectores socioeconómicos más bajos. Sólo el 56,1\% de los inscritos que pertenecen al grupo D estaba inscrito en 2009 , pero el $76,8 \%$ de las personas en este grupo estaba dispuesto a votar si la inscripción hubiera sido automática. Esto es, la diferencia en la participación electoral entre los distintos grupos socioeconómicos declinaría si la inscripción fuese automática. Ahora bien, la tasa de no participación en caso de que la votación fuera voluntaria igual seguiría siendo mayor entre los grupos de nivel socioeconómico más bajo. Así, aunque sólo el 3,8\% del grupo $\mathrm{ABC} 1$ manifestó que no votaría si el voto fuese voluntario, el $23,2 \%$ del grupo $\mathrm{D}$ y el $31,3 \%$ del E señalaron que se abstendrían de votar. Esto confirma lo que nos dice la literatura sobre una menor participación de los grupos de menos ingresos cuando la votación es voluntaria (Franklin 2004; Rubenson, Blais et al. 2004, Lyons y Alexander 2000, Powell 1986: 28). 
Como indica la Tabla $\mathrm{N}^{\circ}$ 4, la disposición a votar entre los nacidos antes y después de 1971 es similarmente alta. El 75,5\% de los nacidos antes de 1971 - y que por lo tanto tenían edad para votar durante la transición - estaba inscrito y manifestó que votaría con voto voluntario. El 4,1\% adicional no estaba inscrito, pero manifestó que votaría si la inscripción fuera automática. Así, el 79,6\% de los nacidos antes de 1971 votaría en caso de inscripción automática y voto voluntario. Entre los nacidos después de 1971, el 37,4\% estaba inscrito y votaría con voto voluntario. El 37\% adicional no estaba inscrito, pero votaría con inscripción automática. En total, el 74,4\% de los nacidos después de 1971 habría votado en el hipotético caso de haber habido inscripción automática y votación voluntaria en 2009.

La Tabla $N^{\circ} 4$ también muestra que el 20,4\% de los nacidos antes de 1971 manifestaba que no votaría en caso de existir inscripción automática y voto voluntario. El $18,4 \%$ de los que no votarían, estaba ya inscrito y el $2,0 \%$ no está inscrito pero igual no votaría en caso de que hubiese habido inscripción automática. A su vez, entre los nacidos después de 1971, el 7,1\% estaba inscrito pero no votaría si el voto fuera voluntario y el $18,5 \%$ no está inscrito y tampoco votaría si la inscripción fuera automática.

TABLA N ${ }^{\circ}$ 4: $\quad$ DISTRIBUCIÓN DE INSCRITOS Y PERSONAS DISPUESTAS A VOTAR POR GRUPOS DE EDAD

\begin{tabular}{|c|c|c|c|c|c|}
\hline & $\begin{array}{l}\text { Inscritos que } \\
\text { votarían con } \\
\text { oto voluntario } \\
\qquad \%\end{array}$ & $\begin{array}{c}\text { Inscritos que } \\
\text { se abstendrían } \\
\text { con voto } \\
\text { voluntario } \\
\%\end{array}$ & $\begin{array}{c}\text { No inscritos } \\
\text { que votarían } \\
\text { con inscripción } \\
\text { automática } \\
\%\end{array}$ & $\begin{array}{l}\text { No inscritos } \\
\text { que no votaría } \\
\text { con inscripción } \\
\text { automática } \\
\%\end{array}$ & $\begin{array}{c}\text { Total } \\
\text { \% (Núm.) }\end{array}$ \\
\hline Nacidos en 1971 o antes & s $\quad 75,5$ & 18,4 & 4,1 & 2,0 & $100(858)$ \\
\hline Nacidos después de 1971 & 7137,4 & 7,1 & 37,0 & 18,5 & $100(644)$ \\
\hline Total & 59,2 & 13,6 & 18,2 & 9,1 & $100(1.502)$ \\
\hline
\end{tabular}

Pearson Chi Square: 453.997** (estadísticamente significativo al 0.001).

Fuente: elaboración propia con datos de Encuesta CEP № 61, octubre 2009. 
La predisposición a votar bien pudiera estar influida por la percepción de la gente sobre la situación económica actual y futura del país, como sugiere la escuela de Rochester. La Tabla $N^{\circ} 5$ muestra la disposición a votar a partir de dicha percepción. Se aprecia una menor predisposición a votar $(70,9 \%)$ entre las personas que consideraban que la situación económica actual del país era mala o muy mala. A su vez, entre los que consideraban que la situación era buena y muy buena, había mayor predisposición a votar (80,9\%). Ocurre algo similar con la pregunta sobre la situación económica futura del país. Las personas más optimistas mostraban mayor predisposición a votar -independientemente de su condición de inscripción — que aquellos que creían que la

TABLA N ${ }^{\circ}$ 5: $\quad$ DISTRIBUCIÓN DE INSCRITOS Y PERSONAS DISPUESTAS A VOTAR POR PERCEPCIÓN ECONÓMICA PRESENTE Y FUTURA

\begin{tabular}{|c|c|c|c|c|c|}
\hline & $\begin{array}{l}\% \text { inscritos } \\
\text { dispuestos } \\
\text { a votar } \\
\text { (a) }\end{array}$ & $\begin{array}{l}\text { \% no inscritos } \\
\text { dispuestos } \\
\text { a votar } \\
\text { (b) }\end{array}$ & $\begin{array}{c}\% \text { dispuestos a } \\
\text { votar (inscritos } \\
\text { y no inscritos) } \\
(\mathrm{c}=\mathrm{a}+\mathrm{b})\end{array}$ & $\begin{array}{l}\% \text { inscritos y no } \\
\text { inscritos que } \\
\text { prefieren no votar } \\
\text { (d) }\end{array}$ & $\begin{array}{c}\text { Total } \\
\% \text { (Núm.) } \\
(\mathrm{e}=\mathrm{c}+\mathrm{d})\end{array}$ \\
\hline \multicolumn{6}{|c|}{ Situación económica actual del país } \\
\hline Mala y muy mala & 55,7 & 15,2 & 70,9 & 29,0 & $100(348)$ \\
\hline Ni buena ni mala & 58,3 & 20,0 & 78,3 & 21,7 & $100(778)$ \\
\hline Buena y muy buena & 63,6 & 17,3 & 80,9 & 19,1 & $100(371)$ \\
\hline No sabe y no contesta & a 60,0 & 20,0 & 80,0 & 20,0 & $100(5)$ \\
\hline Total & 59,1 & 18,2 & 77,3 & 22,7 & $100(1.502)$ \\
\hline \multicolumn{6}{|c|}{ Situación económica futura del país } \\
\hline Mejor y mucho mejor & r 57,3 & 22,7 & 80,0 & 20,3 & $100(751)$ \\
\hline Igual & 60,8 & 14,2 & 75,0 & 25,0 & $100(582)$ \\
\hline Peor y mucho peor & 54,6 & 10,7 & 65,3 & 34,7 & $100(75)$ \\
\hline No sabe y no contesta & 67,0 & 12,8 & 79,8 & 20,2 & $100(94)$ \\
\hline Total & 59,0 & 18,3 & 77,3 & 22,7 & $100(1.502)$ \\
\hline
\end{tabular}

Pearson Chi Square para situación económica actual: 22,526 (no es estadísticamente significativa al 0,001$)$. Pero si se omite la categoría "no sabe/no contesta", los datos son estadísticamente significativos.

Pearson Chi Square para situación económica futura: 3,.764 (estadísticamente significativa al 0,001).

Fuente: Elaboración propia con datos de Encuesta CEP N 61, octubre 2009. 
situación de Chile iba a ser peor o mucho peor en el futuro; aunque aquí la diferencia es sustancialmente menor. Esto parece indicar que una lectura pesimista sobre la situación actual del país tiene mayor fuerza para inducir a la abstención que las expectativas futuras sobre la situación económica.

\subsection{Preferencias políticas y predisposición a votar}

Podríamos pensar que la autoidentificación de las personas en el espectro ideológico influye en su disposición a votar. Las personas con posiciones ideológicas definidas deberían, entonces, estar más inclinadas a participar en los procesos electorales. A su vez, aquellos que no se identifican en la escala ideológica estarían menos dispuestos a votar, presumiblemente, con inscripción automática y voto voluntario. No obstante, la Tabla $\mathrm{N}^{\circ} 6$ no respalda esa hipótesis. Aquellos inscritos que se abstendrían en caso de que el voto fuese voluntario tienen posiciones ideológicas más de izquierda que los inscritos que votarían con voto voluntario. A su vez, entre los no inscritos no hay diferencia en posición ideológica promedio entre los que votarían y los que no votarían con inscripción automática.

La Tabla $\mathrm{N}^{\circ} 6$ también muestra que aquellos dispuestos a votar tienden a su vez, en mayor proporción, a identificarse en la escala ideológica que aquellos que no votarían (ya sea que estén inscritos o no). El 78,1\% de los inscritos que votaría se ubica en la escala ideológica, mientras que sólo el $60,5 \%$ de los inscritos que no votaría se identifica en la escala. A su vez, el $81,4 \%$ de los no inscritos que votaría se ubica en la escala, mientras que sólo el $61,3 \%$ de los no inscritos que no votaría se ubica en la escala.

La Tabla $\mathrm{N}^{\circ} 6$ muestra algunas diferencias entre los inscritos $\mathrm{y}$ los no inscritos respecto a su autoubicación en la escala ideológica y disposición a votar. Hay una mayor predisposición a no ubicarse en la escala ideológica entre aquellos que, estando inscritos, optarían por no votar $(39,5 \%)$ y entre aquellos que, no estando inscritos, también optarían por abstenerse (38,7\%). Pero aquellos que sí votarían presentan mayores probabilidades de identificarse en la escala ideológica, ya sea estando inscritos $(78,1 \%)$ o no estando inscritos $(81,4 \%)$. Ahora bien, en términos de dónde se ubican los inscritos en la escala ideológica, aquellos dispuestos a votar tienden a ubicarse levemente más a la de- 


\section{TABLA N ${ }^{\circ}$ 6: $\quad$ POSICIÓN IDEOLÓGICA SEGÚN CONDICIÓN DE INSCRIPCIÓN Y VOLUNTAD DE VOTAR}

\begin{tabular}{|c|c|c|c|}
\hline & $\begin{array}{l}\text { Posición ideológica } \\
\text { en escala } 1-10^{*} \\
\text { (Desviación estándar) }\end{array}$ & $\begin{array}{c}\% \text { que se } \\
\text { identifica en } \\
\text { posición ideológica }\end{array}$ & $\begin{array}{c}\% \text { que no se } \\
\text { identifica en } \\
\text { escala ideológica } \\
1-10\end{array}$ \\
\hline $\begin{array}{l}\text { Inscritos que votarían } \\
\text { con voto voluntario }\end{array}$ & $\begin{array}{c}5,46 \\
(2,31)\end{array}$ & 78,1 & 21,9 \\
\hline $\begin{array}{l}\text { Inscritos que se abstendrían } \\
\text { con voto voluntario }\end{array}$ & $\begin{array}{c}4,98 \\
(1,82)\end{array}$ & 60,5 & 39,5 \\
\hline $\begin{array}{l}\text { No inscritos que votarían con } \\
\text { inscripción automática }\end{array}$ & $\begin{array}{c}5,06 \\
(2,14)\end{array}$ & 81,4 & 18,6 \\
\hline $\begin{array}{l}\text { No inscritos que no votarían } \\
\text { con inscripción automática }\end{array}$ & $\begin{array}{c}5,10 \\
(1,89)\end{array}$ & 61,3 & 38,7 \\
\hline Total & $\begin{array}{c}5,3 \\
(2,21)\end{array}$ & 74,9 & 25,1 \\
\hline
\end{tabular}

Las diferencias de medias son estadísticamente significativas para los inscritos que votarían con voto voluntario y cada una de las otras categorías, pero no lo son entre las otras tres categorías.

* Posición ideológica en escala donde 1 es izquierda y 10 es derecha.

Fuente: Autores con datos de Encuesta CEP N ${ }^{\circ}$ 61, octubre 2009.

recha (5,46 en la escala $1-10$, donde 1 es izquierda y 10 es derecha) que los inscritos que se abstendrían (4,98). Pero, por otro lado, entre los no inscritos que votarían y los no inscritos que se abstendrían no hay diferencias en su posicionamiento en la escala ideológica $(5,06$ y $5,10)$.

La Tabla $\mathrm{N}^{\circ} 7$ muestra la identificación con los tradicionales "tercios" del espectro ideológico-político y la disponibilidad a votar dadas las distintas condiciones de inscripción. El porcentaje de personas de centro que, estando inscritas, votaría, es menor que en el caso de la derecha y la izquierda. A su vez, el porcentaje de inscritos que se abstendría en caso de que el voto fuera voluntario es mayor entre aquellos que se identifican con el centro y entre los que no se identifican en la escala de los tercios que entre las personas de derecha y de izquierda. La disposición a votar entre los no inscritos también es mayor entre las personas que se identifican con la derecha y con la izquierda que entre 

CONDICIÓN DE INSCRIPCIÓN Y DISPOSICIÓN A VOTAR

\begin{tabular}{|c|c|c|c|c|c|}
\hline & $\begin{array}{c}\text { Derecha } \\
\% \\
\text { (Núm.) }\end{array}$ & $\begin{array}{c}\text { Centro } \\
\% \\
\text { (Núm.) }\end{array}$ & $\begin{array}{c}\text { Izquierda } \\
\% \\
\text { (Núm.) }\end{array}$ & $\begin{array}{c}\text { Ninguna/ } \\
\text { No sabe } \\
\text { no respond } \\
\% \\
\text { (Núm.) }\end{array}$ & $\begin{array}{cc}\text { Total } \\
\text { \% } \\
\text { den (Núm.) }\end{array}$ \\
\hline $\begin{array}{l}\text { Inscritos que votarían } \\
\text { con voto voluntario }\end{array}$ & 67,5 & 60,7 & 62,1 & 53,4 & $100(888)$ \\
\hline $\begin{array}{l}\text { Inscritos que se abstendrían } \\
\text { con voto voluntario }\end{array}$ & 5,3 & 16,4 & 10,0 & 18,3 & $100(204)$ \\
\hline $\begin{array}{l}\text { No inscritos que votarían } \\
\text { con inscripción automática }\end{array}$ & 22,8 & 16,9 & 21,8 & 14,5 & $100(272)$ \\
\hline $\begin{array}{l}\text { No inscritos que no votarían } \\
\text { con inscripción automática }\end{array}$ & 4,3 & 6,0 & 6,1 & 13,8 & $100(9,1)$ \\
\hline Total (N) & $100(302)$ & $100(201)$ & $100(330)$ & $100(668)$ & $100(1.501)$ \\
\hline
\end{tabular}

Pearson Chi Square: 78.412 (estadísticamente significativo al 0.001).

Fuente: elaboración propia con datos de Encuesta CEP Nº 61, octubre 2009.

aquellos que se identifican con la opción "ninguno". Hay evidencia entonces de que la voluntariedad del voto afectaría más negativamente a los partidos de centro y a los movimientos políticos que no se identifican en la escala ideológica, que a los partidos de la derecha y de la izquierda.

\subsection{Simulación de resultados electorales}

La Tabla $\mathrm{N}^{\circ} 8$ muestra una simulación de resultados electorales a partir de la encuesta CEP de octubre de 2009. También aparecen los resultados oficiales de la elección realizada en diciembre de ese año. En la Tabla $\mathrm{N}^{\circ} 8$ se aprecia que, considerando como base sólo a las personas inscritas para votar, la encuesta CEP tuvo una buena capacidad predictiva, anticipando dentro del margen de error la votación obtenida por cada uno de los cuatro candidatos presidenciales.

Nótese que si en vez de considerar sólo a los inscritos (72,6\% de la muestra), se considera a toda la muestra, la votación por el candidato Eduardo Frei aumentaría más allá del margen de error —aunque todavía en línea con lo que finalmente ocurrió en la elección-, mientras que la 
TABLA No 8 :

INTENCIÓN DE VOTO POR CONDICIÓN DE INSCRIPCIÓN Y DISPOSICIÓN A VOTAR (\%)

\begin{tabular}{|c|c|c|c|c|c|}
\hline Candidato & $\begin{array}{l}\text { Sebastián } \\
\text { Piñera }\end{array}$ & $\begin{array}{l}\text { Eduardo } \\
\text { Frei }\end{array}$ & $\begin{array}{l}\text { Jorge } \\
\text { Arrate }\end{array}$ & $\begin{array}{l}\text { Marco Enríquez- } \\
\text { Ominami }\end{array}$ & $\begin{array}{l}\text { z- Total } \\
\text { (Núm.) }\end{array}$ \\
\hline Toda la muestra & 41,5 & 27,9 & 4,9 & 25,7 & $\begin{array}{r}100 \\
(1.505)\end{array}$ \\
\hline Inscritos & 42,6 & 30,2 & 5,3 & 21,9 & $\begin{array}{r}100 \\
(1.093)\end{array}$ \\
\hline No inscritos & 38,3 & 21,9 & 4,2 & 35,6 & $\begin{array}{r}100 \\
(409)\end{array}$ \\
\hline $\begin{array}{l}\text { Inscritos y votarían con } \\
\text { voto voluntario }\end{array}$ & 43,1 & 31,1 & 4,6 & 21,2 & $\begin{array}{r}100 \\
(888)\end{array}$ \\
\hline $\begin{array}{l}\text { Inscritos y no votarían con } \\
\text { voto voluntario }\end{array}$ & 39,8 & 24,8 & 9,0 & 26,3 & $\begin{array}{r}100 \\
(204)\end{array}$ \\
\hline $\begin{array}{l}\text { No inscritos, pero votarían con } \\
\text { inscripción aut. y voto voluntario }\end{array}$ & 42,1 & 20,5 & 3,9 & 33,6 & $\begin{array}{r}100 \\
(273)\end{array}$ \\
\hline $\begin{array}{l}\text { No inscritos y no votarían con } \\
\text { inscripción automática y voto voluntari }\end{array}$ & io 29,4 & 25,5 & 4,9 & 40,2 & $\begin{array}{r}100 \\
(136)\end{array}$ \\
\hline Votarían (inscritos y no inscritos) & 42,8 & 28,5 & 4,5 & 24,2 & $\begin{array}{r}100 \\
(1.161)\end{array}$ \\
\hline $\begin{array}{l}\text { No votarían (inscritos y } \\
\text { no inscritos) }\end{array}$ & 34,9 & 25,1 & 7,2 & 32,8 & $\begin{array}{r}100 \\
(241)\end{array}$ \\
\hline Resultados oficiales de primera vuelta & 44,1 & 29,6 & 6,2 & 20,1 & - \\
\hline Resultados oficiales de segunda vuelta & 51,6 & 48,4 & - & - & - \\
\hline
\end{tabular}

Las diferencias entre inscritos y no inscritos son estadísticamente significativas para los tres candidatos con más votación. Las diferencias para las diferentes combinaciones de inscritos/no inscritos e intención de voto son significativas sólo cuando cambia la condición de inscripción.

Fuente: Elaboración propia con datos de Encuesta CEP N ${ }^{\circ}$ 61, octubre 2009. Hemos normalizado los datos, excluyendo indecisos, para que la votación por los cuatro candidatos sume $100 \%$.

votación por Marco Enríquez-Ominami (ME-O) subiría también significativamente, prediciendo una votación superior a la que finalmente obtuvo el candidato independiente de izquierda.

Ahora bien, las preferencias por Frei y ME-O difieren sustancialmente entre los no inscritos y los inscritos. Entre los no inscritos $(27 \%$ de la muestra), mayoritariamente menores de 40 años, ME-O ocupaba el segundo lugar, apenas por debajo de Sebastián Piñera, mientras que Eduardo Frei caía a un distante tercer lugar. 
Luego mostramos los resultados para las cuatro combinaciones posibles a partir de la condición de inscripción y voluntariedad del voto. Entre los inscritos que igual votarían si el voto fuera voluntario, las preferencias electorales son similares a las observadas entre todos los inscritos. Entre los inscritos que se abstendrían si el voto fuera voluntario hay más simpatizantes de Arrate y de ME-O, lo que evidencia una cercanía de esos candidatos con los electores aparentemente desafectos que votan sólo porque están obligados a hacerlo. Pero entre los inscritos, Frei superaba a ME-O por casi 10 puntos porcentuales.

Finalmente, mostramos la intención de voto de aquellos que, estando o no inscritos, manifestaron que votarían si la inscripción fuese automática y el voto voluntario. Esto es, las preferencias de aquellos que habrían votado si en 2009 hubieran estado ya vigentes las dos reformas que recientemente se han adoptado, la inscripción automática y el voto voluntario. Sorpresivamente, los resultados allí muestran pocas diferencias con las preferencias de los inscritos (los que efectivamente podían votar en 2009) y con los resultados oficiales. Sebastián Piñera apenas mejora su apoyo respecto a los inscritos, pasando de 42,6\% a 42,8\%. Eduardo Frei habría visto bajar su apoyo de 30,2\% entre los inscritos a $28,5 \%$ entre los que hubieran votado de existir inscripción automática y voto voluntario. Marco Enríquez-Ominami habría mejorado su apoyo de forma estadísticamente significativa, pasando de $21,9 \%$ entre los inscritos a $24,2 \%$ entre los votantes probables bajo un sistema de inscripción automática y voto voluntario. Así y todo, el orden de llegada de los cuatro candidatos no se hubiera alterado. Piñera igual habría obtenido el primer lugar, Frei habría llegado en segundo lugar y ME-O habría terminado tercero, aunque a una distancia menor que la que tenía entre los inscritos, y menor también que lo observado el día de la elección.

\subsection{Regresión}

La Tabla $\mathrm{N}^{\circ} 9$ presenta modelos de regresión probabilística que dan cuenta de qué variables explican la posición de los chilenos en las cuatro categorías ya discutidas de inscripción y obligatoriedad de la votación. La categoría de referencia es la de inscritos que sí votarían con voto voluntario. Nótese que, dado que usamos las posiciones políticas izquierda, derecha, centro y ninguna, debemos usar un modelo que re- 
TABLA N ${ }^{\circ}$ 9: $\quad$ MODELOS DE REGRESIÓN PROBABILÍSTICA PARA LAS CUATRO CATEGORÍAS DE VOTANTES

\begin{tabular}{|c|c|c|c|}
\hline & \multicolumn{3}{|c|}{ Categoría de referencia: Inscritos dispuestos a votar } \\
\hline & $\begin{array}{c}\text { Inscritos que } \\
\text { se abstendrían } \\
\text { con voto } \\
\text { voluntario }\end{array}$ & $\begin{array}{l}\text { No inscritos } \\
\text { que votarían } \\
\text { con inscripción } \\
\text { automática }\end{array}$ & $\begin{array}{l}\text { No inscritos que } \\
\text { se abstendrían } \\
\text { con inscripción } \\
\text { automática }\end{array}$ \\
\hline Constante & $\begin{array}{c}-1.093 * * \\
(.184)\end{array}$ & $\begin{array}{c}-3.103 * * \\
(.353)\end{array}$ & $\begin{array}{c}-3.673 * * \\
(.542)\end{array}$ \\
\hline \multicolumn{4}{|l|}{ Sexo } \\
\hline Hombre & $\begin{array}{l}0.031 \\
(.160)\end{array}$ & $\begin{array}{c}-0.012 \\
(.168)\end{array}$ & $\begin{array}{l}0.200 \\
(.216)\end{array}$ \\
\hline Mujer & - & - & \\
\hline \multicolumn{4}{|l|}{ Edad } \\
\hline $18-24$ & $\begin{array}{c}-1.154^{*} \\
(.532)\end{array}$ & $\begin{array}{c}4.173 * * \\
(.368)\end{array}$ & $\begin{array}{l}4.618 * * \\
(0.563)\end{array}$ \\
\hline $25-34$ & $\begin{array}{l}0.050 \\
(.263)\end{array}$ & $\begin{array}{c}3.479 * * \\
(.359)\end{array}$ & $\begin{array}{c}3.910^{* *} \\
(0.555)\end{array}$ \\
\hline $35-54$ & $\begin{array}{l}0.064 \\
(.177)\end{array}$ & $\begin{array}{c}1.043^{* *} \\
(.367)\end{array}$ & $\begin{array}{l}1.196^{*} \\
(.579)\end{array}$ \\
\hline 55 y más & & - & - \\
\hline \multicolumn{4}{|l|}{$G S E$} \\
\hline $\mathrm{ABC} 1$ & $\begin{array}{c}-1.138^{*} \\
(.571)\end{array}$ & $\begin{array}{c}-.275^{* *} \\
(.473)\end{array}$ & $\begin{array}{c}-21.850 \\
(000)\end{array}$ \\
\hline $\mathrm{C} 2$ & $\begin{array}{c}-0.453 \\
(.306)\end{array}$ & $\begin{array}{c}-1.551 * * \\
(.329)\end{array}$ & $\begin{array}{c}-1.659^{* *} \\
(0.454)\end{array}$ \\
\hline $\mathrm{C} 3$ & $\begin{array}{l}0.215 \\
(.168)\end{array}$ & $\begin{array}{c}-0.363^{*} \\
(.180)\end{array}$ & $\begin{array}{c}-0.188 \\
(.225)\end{array}$ \\
\hline D y E & - & - & - \\
\hline \multicolumn{4}{|l|}{ Posición política } \\
\hline Derecha & $\begin{array}{c}-1.396 * * \\
(.286)\end{array}$ & $\begin{array}{c}-0.061 \\
(.223)\end{array}$ & $\begin{array}{c}-1.784 * * \\
(.348)\end{array}$ \\
\hline Centro & $\begin{array}{c}-0.203 \\
(.225)\end{array}$ & $\begin{array}{c}-0.396 \\
(.268)\end{array}$ & $\begin{array}{c}-1.470 * * \\
(.364)\end{array}$ \\
\hline Izquierda & $\begin{array}{l}0.744^{*} \\
(.217)\end{array}$ & $\begin{array}{l}0.232 \\
(.218)\end{array}$ & $\begin{array}{c}-1.005^{* *} \\
(.296)\end{array}$ \\
\hline Ninguna/No sabe/No responde & - & - & - \\
\hline Chi Square & 736.302 & 736.302 & 736.302 \\
\hline-2 log likelihood & 708.311 & 708.311 & 708.311 \\
\hline Cox y Snell & 0.387 & 0.387 & 0.387 \\
\hline Nagelkerke R squared & 0.435 & 0.435 & 0.435 \\
\hline McFadden & 0.221 & 0.221 & 0.221 \\
\hline $\mathrm{N}$ & 204 & 273 & 136 \\
\hline
\end{tabular}

N categoría de referencia: 888 .

Fuente: elaboración propia con datos de Encuesta CEP № 61, octubre 2009. 
quiera variables independientes con categorías de referencia en vez de uno que utilice variables independientes ordinales.

Entre los inscritos que se abstendrían de votar hay más presencia de personas mayores de 35 años. Lógicamente, aquellos menores de 40 años que no tienen predisposición a votar tienen menos probabilidades de estar inscritos. Mientras que entre aquellos que estaban inscritos para la transición a la democracia bien pudo haber aumentado la desafección y por lo tanto las preferencias por abstención en caso de votación voluntaria. A mayor nivel de ingreso, menor es la predisposición a abstenerse entre las personas que ya están inscritas. Por otro lado, en el grupo de inscritos que se abstendrían de votar, la probabilidad de abstención tiende a aumentar entre las personas de centro o entre aquellos que no tienen posición política, y a disminuir entre los que se identifican con la izquierda y con la derecha.

La segunda columna de la Tabla $\mathrm{N}^{\circ} 9$ muestra una regresión que compara las probabilidades de votar entre los no inscritos que hubieran votado con inscripción automática y voto voluntario en 2009 y los inscritos que también expresaron su intención de votar. Los no inscritos más jóvenes tienen mayor disposición a votar. Las personas de menor nivel socioeconómico aparecen como más predispuestas a votar entre los no inscritos, pero esto se debe principalmente a que la mayoría de las personas de nivel socioeconómico más alto están ya inscritas. Así, la inscripción automática y el voto voluntario incorporarían personas de menor nivel socioeconómico simplemente porque las de nivel socioeconómico superior ya están en el padrón.

Finalmente, la tercera columna muestra una regresión que compara a los no inscritos que se abstendrían de votar con los inscritos que sí votarían. Curiosamente, las personas de mayor nivel socioeconómico están sobre-representadas en este grupo. Esto sugiere que el grupo que más fuertemente se define como abstencionista corresponde a aquellos de los sectores socioeconómicos más altos que no están inscritos y no quieren votar. Algo similar ocurre con respecto a la orientación política, los no inscritos que se abstendrían de votar están mayoritariamente alineados en la no identificación política. Las personas que no se identifican en el eje izquierda-derecha y no están inscritas para votar tienen muchas menos probabilidades de hacerlo que aquellas que no estando inscritas sí se identifican en el eje izquierda-derecha. 
Las personas que aparecen como menos dispuestas a abstenerse de votar son aquellas que se identifican con la derecha. En menor medida, aquellas que se identifican con la izquierda también tienen menos probabilidades de abstenerse de votar que aquellas que se identifican con el centro político o las que no se identifican con ninguna tendencia. A su vez, entre quienes ya están inscritos, los más jóvenes parecen tener una disposición a votar más acentuada; asimismo, entre los que no están inscritos, son los jóvenes quienes aparecen más proclives a abstenerse. Esto sugiere que la automatización de la inscripción electoral y la voluntariedad del voto no tendrán un efecto especialmente marcado en la participación electoral de los que hasta 2009 no se habían inscrito. Naturalmente, las dinámicas políticas de cada elección influyen en la participación que eventualmente se dé en cada contienda, pero los resultados de nuestro análisis sugieren que sólo por el hecho de estar automáticamente inscritos, no debería aumentar demasiado la disposición a votar en buena parte de los que no la tenían en 2009. Es más, aunque comiencen a participar nuevos votantes más jóvenes de grupos socioeconómicos más bajos — que hasta 2011 tenían menos probabilidades de estar inscritos-, también dejarán de votar electores de más edad y de grupos socioeconómicos más altos. Así, el número total de electores pudiera no cambiar demasiado, pero la composición del electorado sí cambiará. El promedio de edad de los votantes disminuirá y el peso relativo de votantes de grupos de menos ingresos aumentará.

\section{Conclusión}

Las recientes reformas de voto voluntario e inscripción automática que entrarán en efecto en las elecciones municipales de 2012 introducen un enorme componente de incertidumbre al escenario político chileno. Nadie sabe a ciencia cierta qué ocurrirá con la participación electoral y qué partidos o coaliciones se verán beneficiadas. Usando datos de una encuesta pre-electoral de 2009, hemos indagado sobre la intención de voto y las preferencias políticas de los cuatro grupos posibles de electores, los inscritos con inclinación a votar, los inscritos con inclinación a abstenerse, los no inscritos dispuestos a votar y los no inscritos con inclinación a abstenerse. Hemos mostrado que la encuesta pre-electoral de 2009 sugiere que, al menos en la contienda presidencial de diciembre de 2009, los resultados finales no habrían sido demasiado 
distintos si hubiera existido en ese entonces inscripción automática y voto voluntario, pese a los cambios que estos dos últimos habrían introducido en la composición etaria y nivel socioeconómico del electorado.

Es cierto que cada elección genera distintos incentivos en distintos grupos socioeconómicos y entre personas de diferentes orientaciones políticas para participar. Las elecciones más reñidas tienden a aumentar la participación electoral. En ciertas situaciones de polarización, el electorado también puede reaccionar participando a mayores tasas —o bien absteniéndose cuando las campañas se tornan negativas y los candidatos focalizan sus mensajes en la descalificación de sus rivales. Pero ceteris paribus, la evidencia con datos de la última encuesta realizada antes de las elecciones de 2009 muestra que los resultados finales no habrían variado substancialmente si hubiera habido inscripción automática y voto voluntario. Aunque la participación habría aumentado levemente, el principal cambio se habría dado en la composición del electorado, con más votantes de menos edad — aquellos que cumplieron 18 años después del retorno de la democracia - y pertenecientes a grupos socioeconómicos más bajos.

\section{REFERENCIAS}

Aldrich, J. H. (1993). "Rational Choice and Turnout". American Journal of Political Science, 37 (1): 246-278.

Almond, G. A., y S. Verba (1963). The Civic Culture. Princeton: Princeton University Press.

Angelcos, N. (2011). "Elementos para una crítica de la despolitización en Chile". Revista Observatorio de Juventud, 29 (julio).

Blais, A. (2008a). "Turnout in Elections". En R. J. Dalton y H.-D. Klingemann (eds), Oxford Handbook of Political Behavior. New York: Oxford University Press.

- (2008b). “¿Qué afecta a la participación electoral?” Revista Española de Ciencia Política 18: 9-27.

Blais, A., y K. Carthy (1990). "Does Proportional Representation Foster Voter Turnout?" European Journal of Political Research, 18: 167-181.

Blais, A., L. Massicotte et al. (2003). Why is Turnout Higher in Some Countries than in Others? Ottawa: Elections Canada.

Bonilla, C. A., R. E. Carlin, et al. (2009). "Social or Political Cleavages? A Spatial Analysis of the Party System in Post-Authoritarian Chile." Public Choice (en línea). 
Brunner, J. J. (1998). “Malestar en la sociedad chilena. ¿De qué, exactamente, estamos hablando?" Estudios Públicos, 72: 173-198.

Campbell, A., P. E. Converse, et al. (1960). The American Voter. New York: Wiley.

Cantillana, C. (2009). "Inscritos que no votan: La abstención electoral en Chile y sus factores explicativos". P. Navia, R. Briceño Espinoza y M. Morales (eds.), El genoma electoral chileno. Dibujando el mapa genético de las preferencias politicas en Chile. Santiago: Ediciones Universidad Diego Portales: 77-96.

Carlin, R. (2006). "The Decline of Citizen Participation in Electoral Politics in Post-Authoritarian Chile". Democratization, 13 (4): 632-651.

Contreras, G., F. González et al. (2012) "Nuevo régimen electoral en Chile. Inscripción automática y voto voluntario". En M. Morales y P. Navia (eds.), Democracia Municipal en Chile, 1992-2010. Santiago, Ediciones Universidad Diego Portales (en prensa).

Contreras, G. y P. Navia (2012). "Diferencias generacionales en la participación electoral en Chile: 1988-2010”. Observatorio Electoral, Universidad Diego Portales, Santiago. Manuscrito.

Corvalán, A. y P. Cox (2010). "When Generational Replacement is Class Biased: Chilean Turnout (1989-2008)". New York University. Manuscrito.

Dow, J. K. (1998). “A Spatial Analysis of Candidates in Dual Member Districts: The 1989 Chilean Senatorial Elections". Public Choice, 97: 119-142.

Downs, A. (1957). An Economic Theory of Democracy. New York: Harper \& Row.

(2001). "Teoría económica de la acción política en una democracia". En A. Batlle (ed.), Diez textos básicos de ciencia política. Barcelona: Ariel.

Duch, R. M. y R. T. Stevenson (2008). The Economic Vote. How Political and Economic Institutions Condition Election Results. New York: Cambridge University Press.

Ferejohn, J. y M. Fiorina (1974). “The Paradox of Not Voting: A Decision Theoretic Analysis". American Political Science Review, 68 (2): 525536.

Fontaine, A., C. Larroulet et al. (eds.) (2007). Modernización del régimen electoral chileno. Santiago: CEP/Cieplan/Libertad y Desarrollo/ Proyectamérica.

Fornos, C. A., T. J. Power et al. (2004). "Explaining Voter Turnout in Latin America, 1980 to 2000". Comparative Political Studies, 37 (8): 909-940.

Franklin, M. N. (1996). “Electoral Participation”. En L. LeDuc, R. Niemi y P. Norris (eds.), Comparing Democracies: Elections and Voting in Global Perspective. Thousand Oaks, CA: Sage: 220-242.

(2004). Voter Turnout and the Dynamics of Electoral Competition in Established Democracies Since 1945. New York: Cambridge University Press. 
Fuentes, C., y A. Villar (eds.) (2005). Voto ciudadano. Debate sobre la inscripción electoral. Santiago: FLACSO.

Grofman, B. (1995). "Is Turnout the Paradox that Ate Rational Choice Theory?" En B. Grofman, Information, Participation and Choice: An Economic Theory of Democracy in Perspective. Ann Arbor, Mi: Michigan University Press: 99-103.

Highton, B. (1997). "Easy Registration and Voter Turnout". Journal of Politics, 59 (May): 565-576.

Huneeus, C. (1998). "Malestar y desencanto en Chile: Legados del autoritarismo y costos de la transición”. Papeles de Trabajo. Corporación Tiempo 2000: 63.

Instituto Nacional de la Juventud (2004). "Participación política juvenil: Dilemas y tensiones actuales". Revista Observatorio de Juventud, 4 (diciembre).

Jackman, R. W. (1987). "Political Institutions and Voter Turnout in the Industrial Democracies". American Political Science Review, 81: 405-423.

Jackman, R. W., y R. A. Miller (1995). "Voter Turnout in the Industrial Democracies During the 1980s". Comparative Political Studies, 27 (4 ): 467-492.

Lehmann, C. (1998). "La voz de los que no votaron". Puntos de Referencia, Centro de Estudios Públicos 197.

Lijphart, A. (1997). “Unequal Participation: Democracy’s Unresolved Dilemma. Presidential Address. American Political Science Association 1996”. American Political Science Review, 91 (1): 1-14.

Lipset, S. M., y S. Rokkan (1992). "Estructuras de división, sistemas de partidos y alineamientos electorales". En A. Battle (ed.), Diez textos básicos de ciencia política. Barcelona: Ariel.

López, M. Á. y M. Morales (2005). "La capacidad explicativa de los determinantes familiares en las preferencias electorales de los chilenos". Política, 45: 87-108.

López, M. y S. Pirinoli (2009). “¿Quiénes votaron nulo y blanco en Chile en 1999 y 2005?” En P. Navia, M. Morales y R. Briceño (eds.), El genoma electoral chileno. Santiago: Ediciones Universidad Diego Portales: $97-$ 116.

Lyons, W., y R. Alexander (2000). "A Tale of Two Electorates: Generational Replacement and the Decline of Voting in Presidential Elections". Journal of Politics, 62: 1014-1034.

Miller, W. E., y J. M. Shanks (1996). The New American Voter. Cambridge, MA, Harvard University Press.

Mitchell, G. E. y C. Wlezien (1995). "The Impact of Legal Constraints on Voter Registration, Turnout, and the Composition of the American Electorate". Political Behavior, 17 (2): 179-202.

Montecinos, E. (2007). “Análisis del comportamiento electoral: De la elección racional a la teoría de redes". Revista de Ciencias Sociales, 13 (1): 9-22.

Morales, M. (2011). "Precauciones frente al voto voluntario". En Chile 2010. Sexta Encuesta Nacional UDP: Percepciones y actitudes sociales. Santiago: 59-72. 
Moulián, T. (1997). El Chile actual. Anatomía de un mito. Santiago: LOMArcis.

Navia, P. (2004). "Participación electoral en Chile 1988-2001". Revista de Ciencia Politica, 24 (1): 81-103.

Navia, P., R. Briceño Espinoza et al. (eds.) (2009). El genoma electoral chileno. Dibujando el mapa genético de las preferencias políticas en Chile. Santiago: Ediciones Universidad Diego Portales.

Norris, P. (2004). Electoral Engineering. Voting Rules and Political Behavior. New York: Cambridge University Press.

Ortega Frei, E. (2003). "Los partidos políticos chilenos: Cambio y estabilidad en el comportamiento electoral 1990-2000". Revista de Ciencia Politica, 23 (2).

Parker, C. (2000). Los jóvenes chilenos: Cambios culturales; perspectivas para el siglo XXI. Santiago: Mideplan.

- (2003). "Abstencionismo, juventud y política en Chile actual". Revista de Estudios Avanzados Interactivos, 2 (4): 1-23.

Pérez-Liñán, A. (2001). "Neoinstitutional Accounts of Voter Turnout: Moving Beyond Industrial Democracies". Electoral Studies, 20: 281-297.

PNUD (1998). Informe de desarrollo humano en Chile. Las paradojas de la modernización. Santiago: PNUD.

(1999). Chile: los desafios éticos del presente. Santiago: PNUD.

(2000). Desarrollo humano en Chile. Más sociedad para gobernar el futuro. Santiago: Programa de las Naciones Unidas para el Desarrollo.

- (2004). Desarrollo humano en Chile. El poder, para qué y para quién. Santiago: Programa de las Naciones Unidas para el Desarrollo.

Powell Jr., G. B. (1986). "American Voter Turnout in Comparative Perspective". American Political Science Review, 8 (1): 17-43.

Riker, W., y P. Ordeshook (1968). "A Theory of Calculus of Voting”. American Political Science Review, 62 (1): 25-42.

Rubenson, D., A. Blais et al. (2004). "Accounting for the Age Gap in Turnout”. Acta Politica, 39: 407-421.

Rubilar, F. (2009). “¿El partido por los ninguno? Algunos determinantes de la desafección partidaria en Chile desde 1990 a 2009". Tesis de Licenciatura, Universidad Diego Portales.

Saldaña, J. (2009). "Crisis en la participación electoral y debate sobre la obligatoriedad del voto en Chile”. En P. Navia, M. Morales y R. Briceño (eds.), El genoma electoral chileno. Santiago: Ed. Universidad Diego Portales.

Thezá, M. (2011). “Jóvenes, participación y ciudadanía: ¿Qué investigar?" Revista Observatorio de Juventud, 29 (julio).

Tironi, E. (1999). La irrupción de las masas y el malestar de las elites. Santiago: Grijalbo.

Tironi, E., y F. Agüero (1999). “¿Sobrevivirá el nuevo paisaje político chileno?" Estudios Públicos, 74: 151-168.

Toro, S. (2007). "La inscripción electoral de los jóvenes en Chile. Factores de incidencia y aproximaciones al debate". En A. Fontaine, C. Larroulet, J. A. Viera-Gallo e I. Walker (comps.), Modernización del régimen electoral chileno. Santiago: CEP/Cieplan/ LyD/ Proyectamérica. 
(2008). "De lo épico a lo cotidiano: Jóvenes y generaciones políticas en Chile". Revista de Ciencia Politica, 28 (3): 143-160.

Uhlaner, C. J. (1995). "What the Downsian Voter Weighs: A Reassessment of the Costs and Benefits of Action". En B. Grofman (ed.), Information, Participation and Choice: An Economic Theory of Democracy in Perspective. Ann Arbor: Michigan University Press: 67-79.

Valenzuela, J. S. (1999). "Respuesta a Eugenio Tironi y Felipe Agüero. Reflexiones sobre el presente y futuro del paisaje político chileno a la luz de su pasado”. Estudios Públicos, 75: 273-290.

Wolfinger, R. E., y S. J. Rosenstone (1980). Who Votes? New Haven: Yale University Press. 